\title{
Ice-core dating and chemistry by direct-current electrical conductivity
}

\author{
KENORICK TAYLOR, \\ Water Resources Center, Desert Research Institute, University of Nevada System, Reno, Nevada, U.S.A. \\ RichaRd Alley, \\ Earth System Science Center and Department of Geosciences, Pennsylvania State University, \\ University Park, Pennsylvania, U.S.A. \\ JoE FiacCO, \\ Glacier Research Group, Institute of the Study of Earth, Oceans and Space, University of New Hampshire, \\ Durham, New Hampshire, U.S.A. \\ Pieter Grootes, \\ Quaternary Isotope Laboratory, University of Washington, Seattle, Washington, U.S.A. \\ GREGG LAMOREY, \\ Water Resources Center, Desert Research Institute, University of Nevada System, Reno, Nevada, U.S.A. \\ Paul Mayewski and Mary Jo SPencer \\ Glacier Research Group, Institute for the Study of Earth, Oceans and Space, University of New Hampshire, \\ Durham, New Hampshire, U.S.A.
}

\begin{abstract}
Although quantitative interpretation of the low-frequency electrical conductivity of ice cores from central Greenland is complicated by temperature variations of the measured core, annual layers can be recognized in sections of the core that are not impacted by non-seasonal features. Ambiguities in counting of annual layers can be minimized by comparing the electrical conductivity measurements to measurements of dust concentration and visual stratigraphy. A non-linear relationship between applied voltage and the current measured across two electrodes complicates the quantitative comparison of measurements made with different equipment, but does not affect the overall shape of the observed features.
\end{abstract}

\section{INTRODUCTION}

The direct-current electrical conductivity method (ECM) of measuring the low-frequency electrical conduction of ice cores is both fast $(\mathrm{min} / \mathrm{m}$ of measurements) and has high spatial resolution (a few millimeters). Because of the relative ease with which ECM can be used to obtain highresolution continuous records, it has been used extensively in a reconnaissance mode to direct more labor-intensive measurements. Because the ECM is responding to the acidity of the ice, it is well suited to detecting the presence of volcanic influences on core chemistry (Hammer, 1980, 1983; Legrand and others, 1987), thus allowing correlation between cores (Clausen and Hammer, 1988; Langway and others, 1988). Identification of annual layers with ECM was used during the Greenland Ice Sheet Program 1 (Neftel and others, 1985) to assist in dating the core. Here, we demonstrate that ECM identified seasonal variations in the strong acid concentration in ice from the Greenland Ice Sheet Project 2 (GISP2; $72^{\circ} 58^{\prime} \mathrm{N}, 38^{\circ} 46^{\prime} \mathrm{W}$ ) site in central Greenland, thus aiding in dating of the GISP2 core. We also show the complications of using ECM in a quantitative manner due to the influence of temperature and applied voltage.

The instrumentation is similar to that described by Hammer (1980). A microtome knife that is rigidly held a fixed distance from the center of the core (perpendicular to the core axis) is used to remove irregularities from a surface along the axis of a section of core. Two electrodes, with a potential difference typically greater than $2000 \mathrm{~V}$, are dragged along the prepared surface (along the depth axis) and the current flowing through the ice is measured. The electrodes are held by a moving carriage so the path and contact force (determined by a weight) can be 
accurately reproduced. The contact area of each electrode is approximated by an ellipse with axes of $2 \mathrm{~mm}$ by $1 \mathrm{~mm}$ with the major axis oriented along the direction of travel. The electrodes are $1 \mathrm{~cm}$ apart. The carriage is moved by a motor drive at speeds of 8 $10 \mathrm{~cm} \mathrm{~s}^{-1}$ and the position of the carriage is sensed by an optical encoder. A constant-voltage $( \pm 0.005 \%)$ power supply is used. The current flowing through the electrodes is digitized every millimeter along the core and stored in a computer. Temperature is measured on the surface of the ice and at $0.5 \mathrm{~cm}$ below the surface through a $1.5 \mathrm{~mm}$ diameter access hole. Additional information about the core, such as depth, time of recovery, location of breaks and fractures, and ice temperature are also stored in the computer.

The system differs from that described by Hammer (1980) in two ways: (1) a higher voltage is used to produce a larger signal to noise ratio; and (2) a rail system is used to transport the electrodes in a repeatable fashion. Schwander (1984) also described a system that uses a rail system and digital recording but which operates at a lower applied voltage.

\section{INFLUENCES ON THE ECM SIGNAL}

The practice in the field is to measure each piece of core twice without shaving the surface between runs. The current values measured during the two runs are nearly always within a few per cent of each other, demonstrating the excellent short-term repeatability of the measurement. Occasionally, the second run will be more than $5 \%$ lower than the first run. If the surface is prepared a second time by shaving with the microtome knife, subsequent measurements will repeat without shaving between the measurements. This suggests that the cause of the discrepancy in the first case had to do with the way the surface was initially prepared and is not a property of the ice.

Over longer time-scales, the measurements are not as repeatable. A $1 \mathrm{~m}$ section of core from $374 \mathrm{~m}$ (Fig. 1a) was measured 24 times over a 2 month period. During this time, the temperature of the core was varied in a random sequence from $-17^{\circ}$ to $-28^{\circ} \mathrm{C}$. Although the shape of features in the ECM record remained unchanged during this time, the value of the ECM for any particular feature was found to vary. The lowering of the ECM signal as the temperature of the ice is reduced is well known (Neftel and others, 1985). However, we observed that the ECM value of a given feature varied by up to $\pm 15 \%$, even when the core was brought back to within a few tenths of a degree of previous measurements and allowed to stabilize for $24 \mathrm{~h}$ (Fig. 1b). This suggests that the qualitative information in the ECM trace is robust, but that quantitative uses of the ECM must proceed carefully as long-term repeatability may be limited, even though short-term repeatability can be demonstrated. A likely cause for the lack of long-term repeatability is the sensitivity of the ECM to the condition of the electrode/ ice contact. A better measurement approach that may alleviate the poor long-term repeatability is a fourelectrode array (two current electrodes and two potential electrodes). Such an array is not as influenced by the
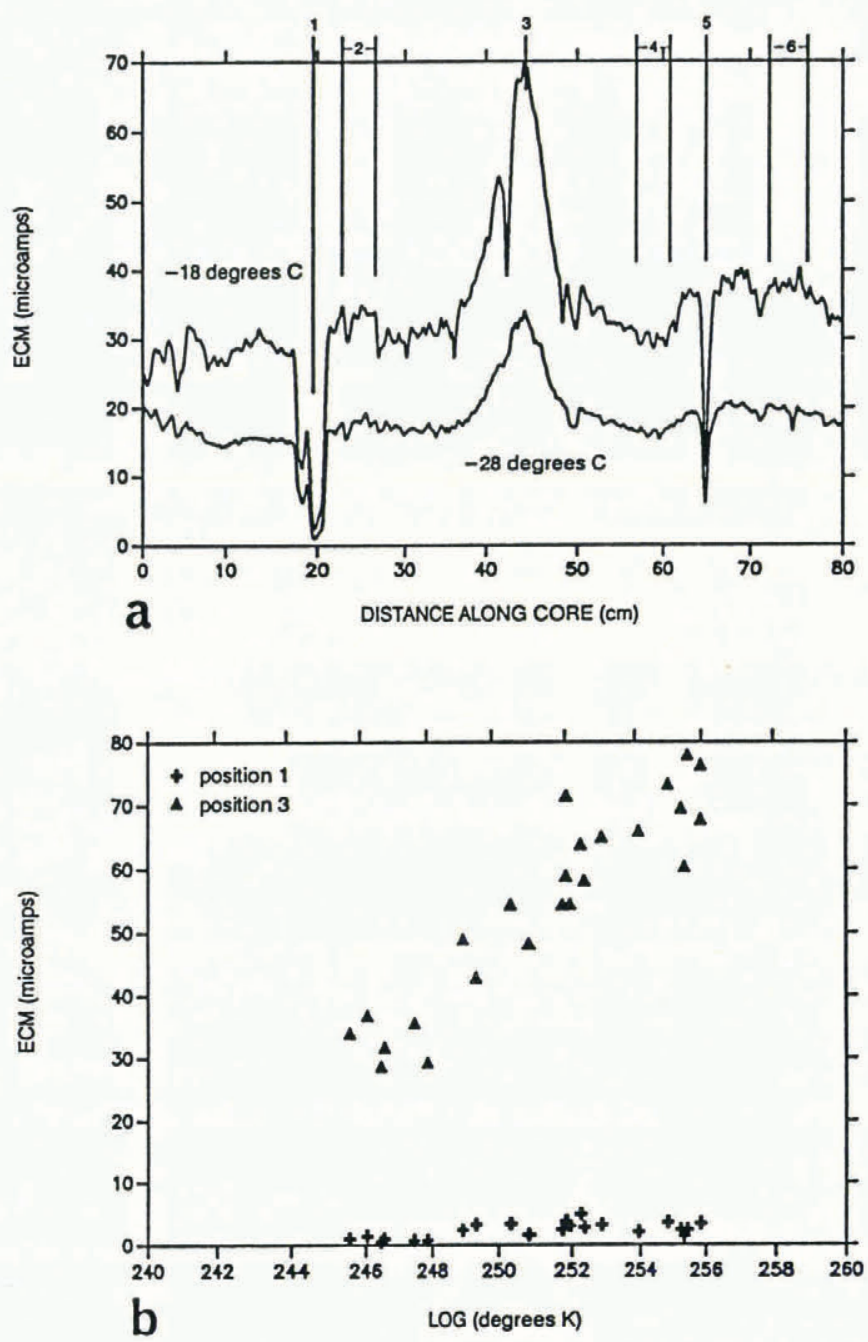

Fig. 1. a. ECM records from $154 \mathrm{~m}$ recorded at $-18^{\circ}$ and $-28^{\circ} \mathrm{C}$. The positions of the features that were used to determine the activation energy are indicated along the top axis. Features 2, 4 and 6 were averaged over the $5 \mathrm{~cm}$ intervals shown. $b$. The ECM value for positions 1 and 3 (see Fig. 1a) as a function of temperature. The temperatures are in Kelvin to allow plotting on a logarithmic axis. Although the ECM value is a function of temperature, the relative relationship of the features is independent of temperature.

electrode/ice contact as the two-electrode array commonly used.

The repeated measurement of the ECM trace at different temperatures allowed the activation energy to be calculated. Following Neftel and others (1985) and assuming an Arrhenius-type dependence of temperature on the ECM, we calculate an activation energy of $0.45 \pm 0.035 \mathrm{eV}$. This is based on 24 measurements of six features in a core from $374 \mathrm{~m}$ over the temperature range of $-17^{\circ}$ to $-28^{\circ} \mathrm{C}$. The data indicate that there is no influence of the value of the ECM on the activation energy. This activation energy is significantly different from the value of $0.23 \pm 0.05 \mathrm{eV}$ reported by Neftel and others (1985) for Greenland ice impacted by the Laki eruption. The discrepancy may be due to the wider temperature range $\left(-18^{\circ}\right.$ to $\left.-40^{\circ} \mathrm{C}\right)$ used in Neftel's measurements. The choice of activation energy will have 


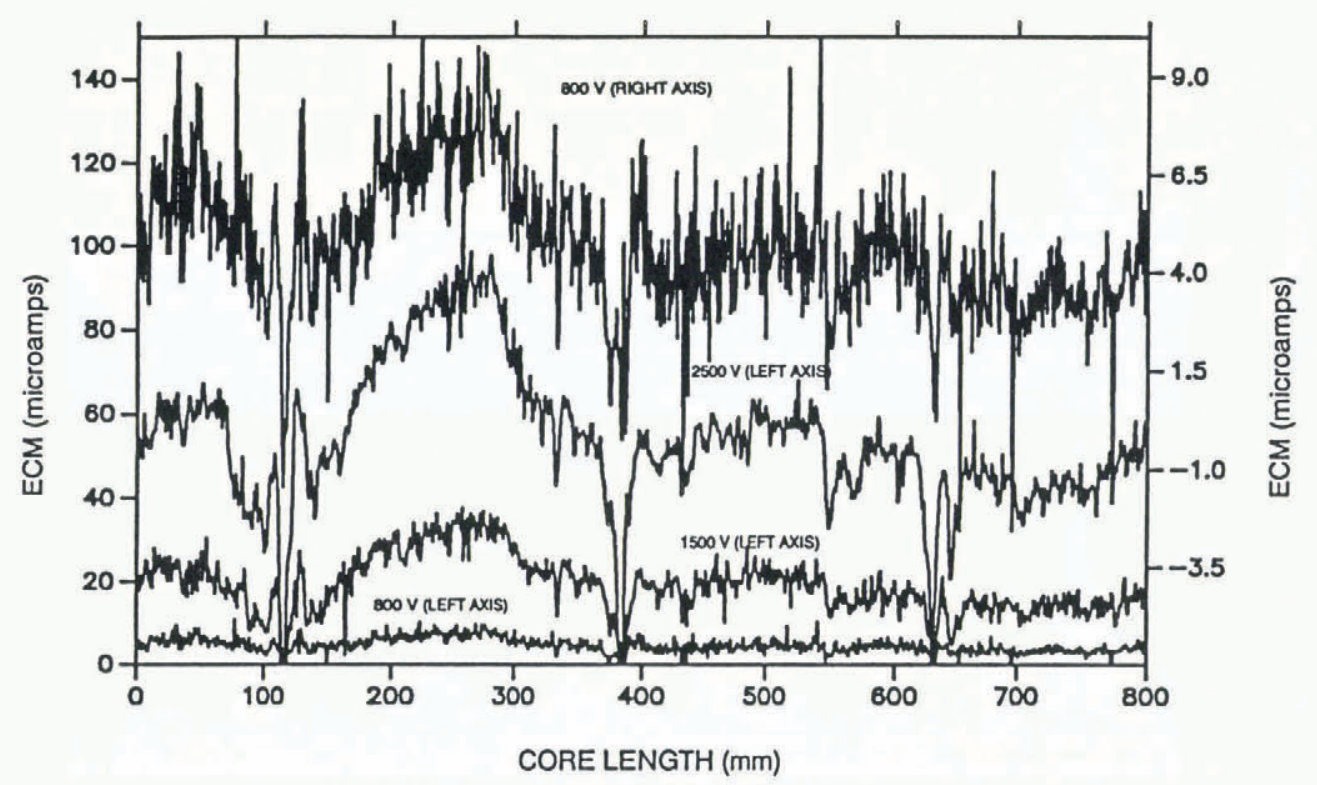

Fig. 2. The ECM trace from a depth of $95 \mathrm{~m}$ as recorded with an applied voltage of 800,1500 and $2500 \mathrm{~V}$. In order to facilitate comparison, the $800 \mathrm{~V}$ trace is plotted twice, corresponding to the left and right axes. Although the amplitude of features varies non-linearly with the applied voltage and the signal to noise ratio is different, the character of features is not a function of the applied voltage.

an impact when quantitatively comparing measurements made on cores that are at different temperatures, and hence must be corrected for temperature effects. This situation commonly occurs for cores that are processed in the field where the temperature of the work and storage areas can vary considerably during the course of a project. The general form of the ECM signal for a given piece of core is not affected by the temperature variation; only the absolute amplitude of the signal is affected.

Another impact on the ECM is the voltage which is applied to the electrodes. Application of voltages in the range of 200-3000 $\mathrm{V}$ has demonstrated that, although the shape of the ECM signal is not influenced by the voltage, the value of the ECM signal increases in a non-linear manner with increasing applied voltage (Fig. 2). In effect, increases in the applied voltage act as a scaling factor which increases the magnitude of the ECM signal but does not alter the shape of the ECM trace. The scaling factor is not linear with respect to voltage as would be suggested by a simple application of Ohm's law.

This non-linear dependence of the ECM signal on voltage complicates the quantitative comparison of measurements made on different ECM systems. A possible explanation for the non-linear relation between the applied voltage and ECM is related to heating at the electrodes. Although the current is small $\left(10^{-5}-10^{-6} \mathrm{~A}\right)$, the surface over which the power is dissipated is small $\left(2 \times 10^{-6} \mathrm{~m}^{2}\right)$ and the voltage is high $(200-3000 \mathrm{~V})$; this results in power densities available for heating at the surface of the electrodes of greater than $10 \mathrm{~kW} \mathrm{~m}^{-2}$. Increased heating at the electrodes is expected to cause a thin water film to form at the electrode/ice contact. Such a film would improve the electrical contact and result in an increase in current flow and hence a higher ECM value.

To gain an insight into the effect of core chemistry on the ECM, a section of the GISP2 core from 101-104 m
(Fig. 3) was analyzed in detail. This section contains the three most commonly observed features in the ECM record: (1) an apparent annual oscillation; (2) a peak which contains volcanic ash $(101.5 \mathrm{~m})$; and (3) a pronounced low $(103.8 \mathrm{~m})$. The low features are common through the core and are characterized by an abrupt short-duration decrease in ECM. Chemical analyses were made on discrete samples of ice approximately $2 \mathrm{~cm}$ long. To compare statistically the chemistry to the ECM, the ECM trace was averaged over the same intervals corresponding to the discrete chemical analysis. All ECM data for the 101-104 $\mathrm{m}$ interval were recorded at a uniform temperature $\left(-18^{\circ} \mathrm{C}\right)$, thus eliminating the need to apply a temperature correction. Chemical analysis included $\mathrm{H}^{+}, \mathrm{SO}_{4}=, \mathrm{NO}_{3}^{-}, \mathrm{NH}_{4}^{+}, \mathrm{Cl}^{-}, \mathrm{K}^{+}$, $\mathrm{Ca}^{++}, \mathrm{Na}^{+}$and $\mathrm{Mg}^{++} \cdot \mathrm{H}^{+}$was determined by strong acid titration and the other species were determined by ion chromatography. A good charge balance supports the assumption that these are the only major species present. An intrinsic difficulty with this type of comparison is that the electrical properties are measured on ice, while the chemistry is measured on a melted sample. During the melting process, soluble particles will be dissolved. The soluble particles are likely to have a negligible effect on the electrical properties of the ice; however, they may affect the aqueous chemistry. Definitive delineation of the influence of chemistry on the ECM is not possible through experiments such as those here, unless soluble particle-free ice with a natural crystal fabric is used.

Two intervals were selected for correlation analysis: (1) the entire interval $101-104 \mathrm{~m}$, which includes the volcanic peak and ECM low; and (2) the interval between 101.5 and $103.8 \mathrm{~m}$ which does not contain the two anomalous events but appears to include several annual oscillations. Table 1 shows the correlation coefficient of each species to the ECM and the percentage of the total ionic balance accounted for by 


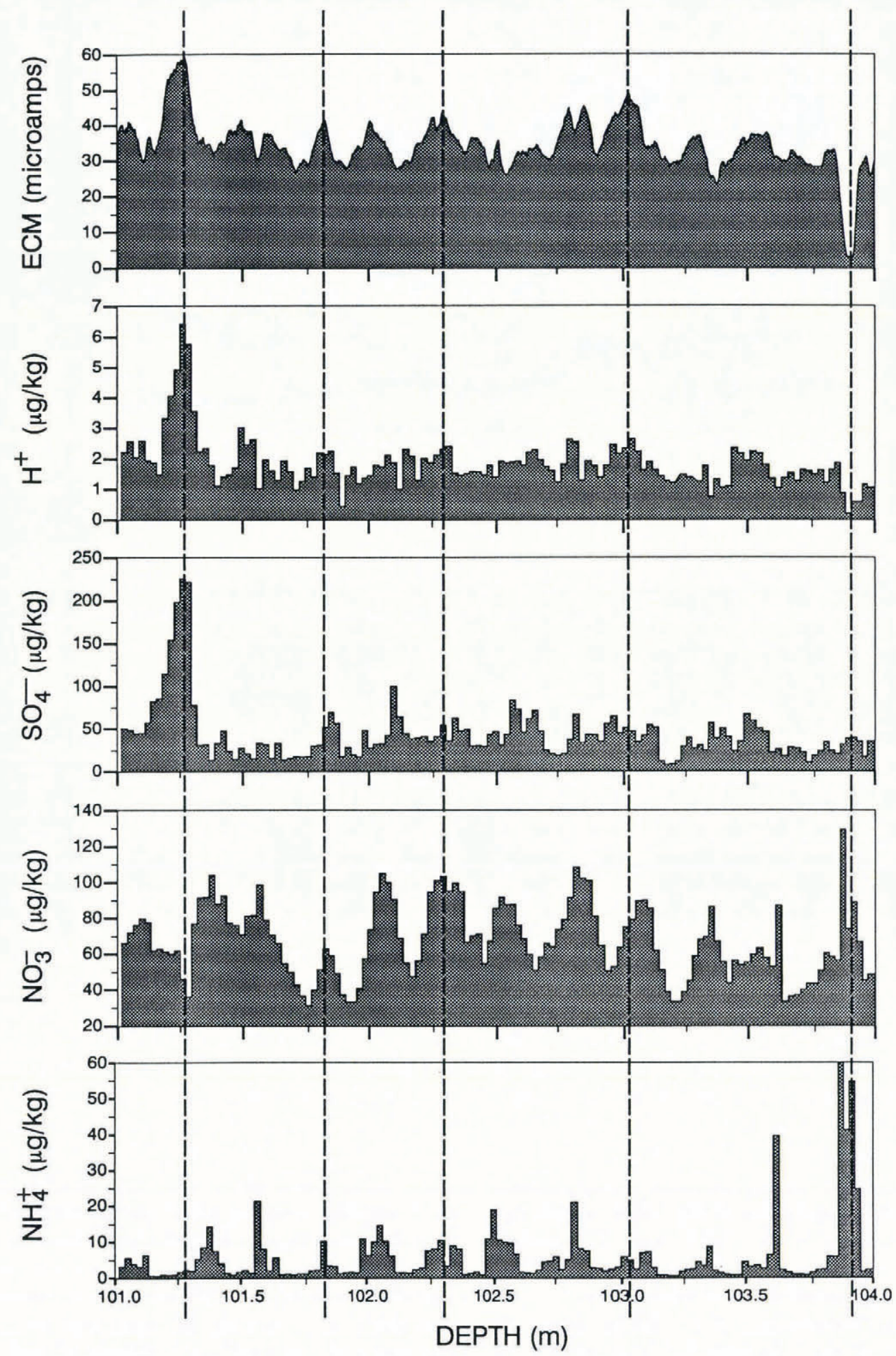

Fig. 3. Comparison of the ECM signal to $\mathrm{H}^{+}, \mathrm{SO}_{4}=\mathrm{NO}_{3}^{-}$and $\mathrm{NH}_{4}{ }^{+}$for the interval from 101 to $104 \mathrm{~m}$. The dashed vertical lines are included to facilitate comparison.

each species. The per cent of the ionic balance is important because the influence of a particular species on the ECM may be lost in noise if the species is only a small part of the total ions in the sample.

$\mathrm{H}^{+}$is the only species that has a correlation significance greater than $99 \%$ in both intervals. This supports the belief that $\mathrm{H}^{+}$is the dominant control on the ECM signal (Hammer, 1980; Schwander and others, 1983). If linear regression models are constructed for the two intervals using only those species which have a correlation coefficient that is statistically significant at the $99 \%$ confidence level, the models shown below are obtained.

For the interval from 101 to $104 \mathrm{~m}$ (all features), the model $\left(R^{2}=0.63\right)$ is:

$\mathrm{ECM}=5.776 \mathrm{H}^{+}+0.001 \mathrm{SO}_{4}=-0.235 \mathrm{NH}_{4}{ }^{+}+24.94$. 


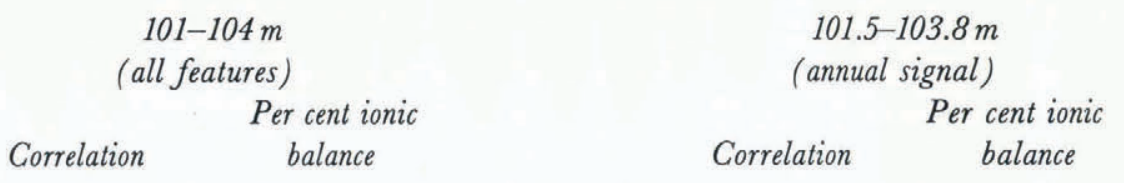

\begin{tabular}{|c|c|c|c|c|}
\hline $\mathrm{H}^{+}$ & $0.74^{*}$ & 29 & $0.54^{*}$ & 30 \\
\hline $\mathrm{NO}_{3}^{-}$ & 0.06 & 22 & $0.43^{*}$ & 23 \\
\hline $\mathrm{SO}_{4}^{-}$ & $0.52^{*}$ & 19 & 0.14 & 18 \\
\hline Non-sea salt ${ }^{\dagger} \mathrm{SO}_{4}=$ & $0.54^{*}$ & 17 & 0.20 & 16 \\
\hline $\mathrm{NH}_{4}^{+}$ & $-0.47^{*}$ & 7 & 0.09 & 5 \\
\hline $\mathrm{Cl}^{-}$ & 0.06 & 7 & $-0.33^{*}$ & 8 \\
\hline $\mathrm{Na}^{+}$ & -0.12 & 5 & $-0.34^{*}$ & 5 \\
\hline $\mathrm{K}^{+}$ & -0.04 & 1 & -0.03 & 1 \\
\hline $\mathrm{Mg}^{++}$ & -0.14 & 2 & $-0.28^{*}$ & 2 \\
\hline $\mathrm{Ca}^{++}$ & -0.17 & 7 & $-0.25^{*}$ & 7 \\
\hline Number of cases & 126 & & 98 & \\
\hline $\begin{array}{l}99 \% \text { critical } \\
\text { value }\end{array}$ & 0.23 & & 0.25 & \\
\hline
\end{tabular}

* Indicates statistically significant correlation at the $99 \%$ confidence interval.

${ }^{\dagger}$ Non-sea salt $\mathrm{SO}_{4}==\mathrm{SO}_{4}=0.103 \mathrm{Cl}^{-}\left(\mu \mathrm{eq} \mathrm{kg}{ }^{-1}\right)$.

For the interval from 101.5 to $103.8 \mathrm{~m}$ (annual signal), the model $\left(R^{2}=0.47\right)$ is:

$$
\begin{aligned}
\mathrm{ECM}= & 3.667 \mathrm{H}^{+}+0.964 \mathrm{NO}_{3}^{-}-0.082 \mathrm{Cl}^{-}-0.070 \mathrm{Na}^{+} \\
& +1.408 \mathrm{Mg}^{++}-0.350 \mathrm{Ca}^{++}+23.16
\end{aligned}
$$

These models show the strong dependence of the ECM signal on $\mathrm{H}^{+}$. The models also show how the apparent relation of chemical species on the ECM can be strongly affected by the types of features that are present in the segment which is analyzed. Hammer (1980) suggested a power-law dependence of ECM on $\mathrm{H}^{+}$with the following form:

$$
\mathrm{ECM}=\mathrm{C}_{1}\left(\mathrm{H}^{+}\right)^{\mathrm{C}_{2}}
$$

A least-squares fit of the data from 101 to $104 \mathrm{~m}$ to this model results in the following values:

$$
\mathrm{ECM}=25^{*}\left(\mathrm{H}^{+}\right)^{0.54} .
$$

The model only explains $55 \%$ of the variance. Hammer (1980) reported a value for $\mathrm{C}_{2}$ of 0.58 for ice from Dye 3, Greenland. Legrand and others (1987) reported values for $\mathrm{C}_{2}$ of 0.63 and 0.42 for data from Vostok and South Pole, respectively. These values are close to the $95 \%$ confidence interval $(0.54 \pm 0.08)$ for $C_{2}$ reported here. The value of $\mathrm{C}_{1}$ is a function of the instrumentation used in the study and is not an intrinsic property of the method. The generally poor fit and wide variability of the models with only $\mathrm{H}^{+}$suggests that additional species or other factors have a minor influence on the ECM.

In the interval that is not affected by the obvious volcanic peak and abrupt ECM low (101.5-103.8 m), an oscillation is present. In this section, the correlations between the ECM and $\mathrm{NO}_{3}^{-}, \mathrm{Na}^{+}, \mathrm{Cl}^{-}, \mathrm{Mg}^{++}$and $\mathrm{Ca}^{++}$are significant at the $99 \%$ confidence interval. Of these, $\mathrm{NO}_{3}^{-}$has the highest correlation $(0.43)$ and is believed to be associated with seasonal inputs of nitric acid, the $\mathrm{H}^{+}$of which is the cause of the apparent annual oscillation that is visible in this section of the ECM record.

\section{APPLICATION OF EGM TO DATING OF ICE CORES}

The use of the ECM to locate the depth in the ice at which volcanic eruptions of known dates are recorded is a reliable method for determining occasional dates along an ice core (Hammer and others, 1978). Because this method depends on historical records, it can only be used over approximately the last 1000 year. However, even when absolute dates are not available, major volcanic eruptions can serve as reference horizons to correlate various cores.

Absolute dates can be obtained by counting annual layers in ice cores. Many factors are known to vary annually, including chemistry (Mayewski and others, 1990), isotopic composition (Dansgaard and others, 1985), dust concentration (Hammer and others, 1978) and appearance (visual stratigraphy; Benson, 1962). 

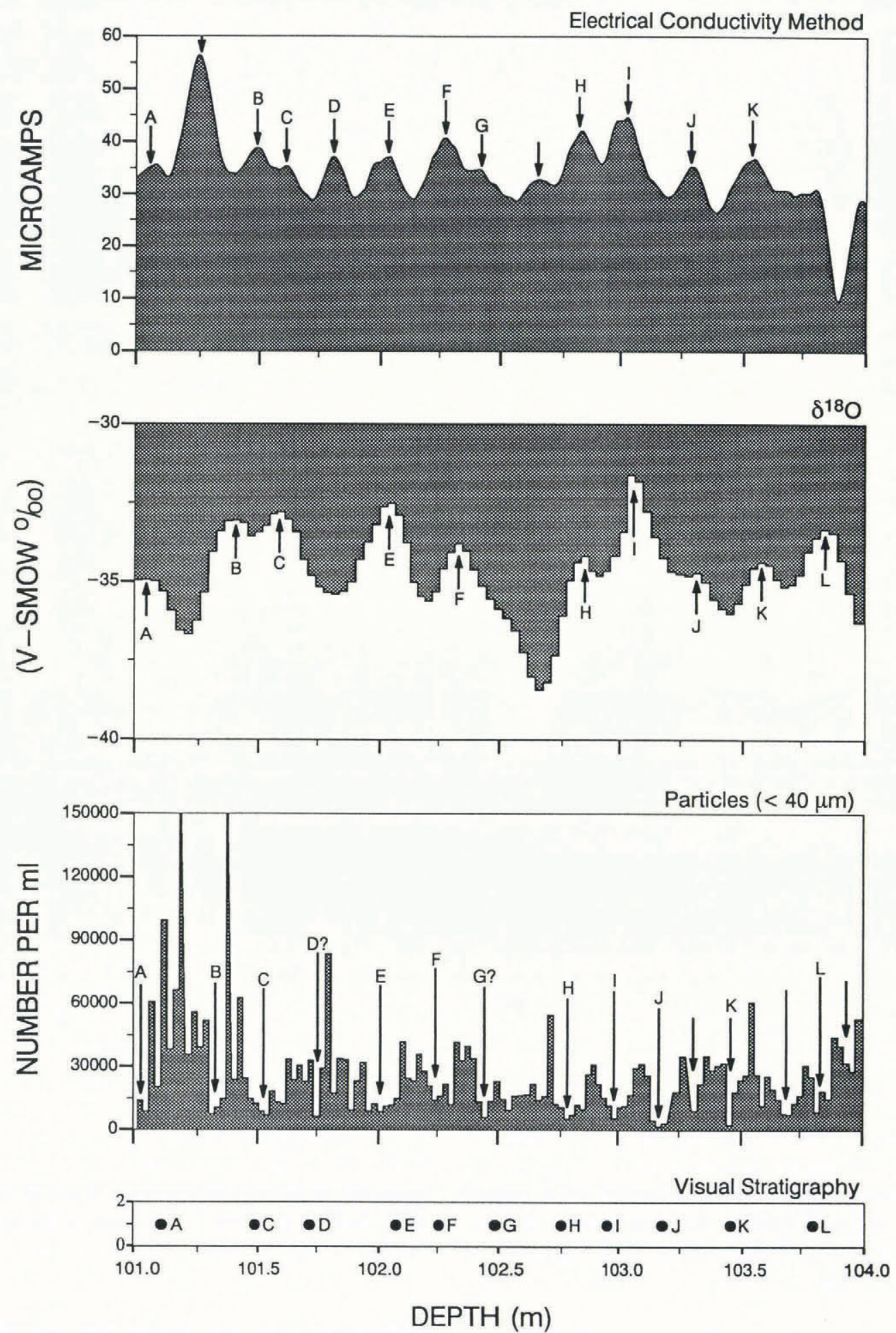

Fig. 4. Comparison of the ECM, $\delta^{18} \mathrm{O}$, particles concentration and visual stratigraphy for the interval 101-104 m. Features that were interpreted to be annual layers based on a single record are indicated by an arrow. Features that were interpreted to be an annual layer on three or more records are indicated by an arrow and a letter.

Long-term records typically include ambiguous events, however, so that any two of these records will differ by a few per cent. To resolve ambiguities, at least three annually varying components must be measured. Visual stratigraphy can be observed rapidly on a light table and particulate concentration can be measured rapidly using a laser system, but chemical and isotopic analyses are slow, expensive and thus not suited for dating long cores.

The previous section demonstrated that, although the absolute value of the ECM signal over a given section of core is influenced by temperature and applied voltage, and has a limited long-term repeatability, the shape of the trace does not vary. Three major features are observed in the ECM trace: (1) volcanic activity; (2) ECM lows; and (3) annual layers. In sections of the core when the nonseasonal influences are absent, the ECM can be used to assist in the identification of annual layers.

Data on annually varying parameters from 101 to $104 \mathrm{~m}$ are plotted in Figure 4 and events that appear to be annual signals are indicated with arrows. The high- 
frequency components of the ECM trace were removed by averaging the trace over $4 \mathrm{~cm}$, which at this depth corresponds to approximately one-fifth of a year. The seasonal variations in $\delta^{18} \mathrm{O}$ concentration yields high $\delta^{18} \mathrm{O}$ values in summer and low values in winter related to air temperature at the time of deposition. The particulate concentration, which is influenced by seasonal changes in wind speed and source areas, was determined with Coulter-counter methods (but laser-scattering techniques are being used on the GISP2 core subsequently, and yield similar results more rapidly). The annual-layer picks determined by visual stratigraphy were chosen by noting the occurrence of one or more rapid oscillations in grain-size and density on the scale of $1 \mathrm{~cm}$. These features, which were observable on a light table, correspond to original depth hoar and wind slabs. The tops of the oscillation zones were selected as the index for the visualstratigraphy pick.

All four seasonal indicators have problems. The ECM has non-seasonal components superimposed on the annual signal; for example, the volcanic peak at $101.5 \mathrm{~m}$ may be misinterpreted as an annual peak, while the anomalous low at $103.8 \mathrm{~m}$ masks an annual peak. Diffusion of isotopes may obscure some years in the $\delta^{18} \mathrm{O}$ record. At some depth, which is in excess of $200 \mathrm{~m}$ for the GISP2 site, diffusion will obscure all evidence of annual layers in the $\delta^{18} \mathrm{O}$ record. Comparison with the other records shows that a clear change in slope in the $\delta^{18} \mathrm{O}$-depth curve also indicates the position of an annual layer ("G"), which was not initially identified. The particulate record also has non-seasonal contributions such as volcanic particulates. However, particulates do not have the diffusion-related concerns that are associated with $\delta^{18} \mathrm{O}$. Visual stratigraphy can also be misleading due to erratic firnification or depositional events and becomes less clear with increasing age and depth owing to densification and other physical changes. However, when several of the above methods are compared, the discrepancies become fairly clear. In Figure 4, each parameter was interpreted and possible years marked by arrows. These were then compared and a year was accepted (and labeled with a letter) if it appeared in three of the four records. Several proposed years were present only in one record and were discarded, but broad agreement is evident. Furthermore, if the accurate but labor-intensive isotopic analysis were eliminated and a year accepted if it appeared in two of the remaining three records, the dating would be unchanged. It is, thus, possible to count annual layers in the upper part of the GISP2 core (and probably other cores) rapidly using only ECM, particulates and visible strata. If only two records are available, counting annual layers becomes less certain because there is no way to reconcile discrepancies between records. However, an indication of possible error limits can be determined. If only one record is available, it is not even possible to recognize problem areas and dating the core by counting annual layers becomes speculative.

Sections of the core will not be suitable for counting of annual layers because of poor core quality or because the seasonal signal in the parameters being monitored is obscured by non-seasonal influence such as volcanism. In these intervals, an extrapolation approach will be required to estimate the time period represented by the segment of core where annual layers cannot be counted. In most deep cores, a zone of brittle ice extending for many hundreds of meters is encountered, which adversely impacts the core quality. In this interval, it is likely to be difficult to perform the measurements discussed here and interpolation will be required.

\section{DISCUSSION}

In most glaciological or paleoclimate investigations, we are rarely interested in the electrical properties of the ice. Instead, we use electrical measurements as a tool to address more pertinent issues, such as core dating and as a pointer for directing more specific investigations. Currently, more specific measurements are so time-consuming that continuous measurements have to be made with a low-time resolution. This can result in aspects of the paleoclimatic story preserved in the core being missed. However, the greater time resolution of the ECM can alert us to look in detail at significant sections. The strong point of the ECM method is that it can be done continuously with high time resolution to identify shortduration events such as annual layers and volcanic events, and to support other more specific measurements.

\section{ACKNOWLEDGEMENTS}

The authors would like to express their appreciation to $\mathrm{R}$. McArthur of the Desert Research Institute, University of Nevada System, for his guidance on the statistical part of this work. This is contribution number GISP2 91-10 of the Greenland Ice Sheet Project Two (GISP2).

\section{REFERENCES}

Benson, C. S. 1962. Stratigraphic studies in the snow and firn of the Greenland ice sheet. SIPRE Res. Rep. 70.

Clausen, H. B. and C. U. Hammer. 1988. The Laki and Tambora eruptions as revealed in Greenland ice cores from 11 locations. Ann. Glaciol., 10, 16-22.

Dansgaard, W., H.B. Clausen, N. Gundestrup, S.J. Johnsen and C. Rygner. 1985. Dating and climatic interpretation of two deep Greenland ice cores. In Langway, C. C., Jr, H. Oeschger and W. Dansgaard, eds. Greenland ice core: geophysics, geochemistry, and the environment. Washington, DC, American Geophysical Union, 71-76. (Geophysical Monograph 33.)

Hammer, C. U. 1980. Acidity of polar ice cores in relation to absolute dating, past volcanism, and radio-echoes. 7. Glaciol., 25(93), 359-372.

Hammer, C. U. 1983. Initial direct current in the buildup of space charges and the acidity of ice cores. 7 . Phys. Chem., 87, 4099-4103.

Hammer, C. U., H.B. Clausen, W. Dansgaard, N. Gundestrup, S.J. Johnsen and N. Reeh. 1978. Dating of Greenland ice cores by flow models, isotopes, volcanic debris, and continental dust. F. Glaciol., 20(82), 3-26.

Langway, C. C., Jr, H. B. Clausen and C. U. Hammer. 
1988. An inter-hemispheric volcanic time-marker in ice cores from Greenland and Antarctica. Ann. Glaciol., 10, 102-108.

Legrand, M., J.- R. Petit and Ye. S. Korotkevich. 1987. D.C. conductivity of Antarctic ice in relation to its chemistry. 7. Phys. (Paris), 48, Colloq. C1, 605-611. (Supplément au 3.)

Mayewski, P.A., M.J. Spencer, M.S. Twickler and S. Whitlow. 1990. A glaciochemical survey of the Summit region, Greenland. Ann. Glaciol., 14, 186-190.

Neftel, A., M. Andrée, J. Schwander, B. Stauffer and C. U. Hammer. 1985. Measurements of a kind of DCconductivity on cores from Dye 3. In Langway, C. C., Jr, H. Oeschger and W. Dansgaard, eds. Greenland ice core: geophysics, geochemistry, and the environment. Was- hington, DC, American Geophysical Union, 32-38. (Geophysical Monograph 33.)

Schwander, J. 1984. Air enclosure of atmospheric air in ice from Greenland and Antarctica and measurements of the electrical conductivity of ice samples for climatological applications. (Ph.D. thesis, Universität Bern.)

Schwander, J., A. Neftel, H. Oeschger and B. Stauffer. 1983. Measurement of direct current conductivity on ice samples for climatological applications. 7. Phys. Chem., 87, 4157-4160.

The accuracy of references in the text and in this list is the responsibility of the authors, to whom queries should be addressed.

MS received 4 June 1991 